\title{
Investigation of the transport of aflatoxin M1 by the transporter ABCG2 in bovine mammary epithelial cells")
}

\author{
YANYING ZHANG, NA ZHANG, DAN CHEN, GUANG HUANG, HUI CAO
}

The Key Laboratory of Dairy Science of Education Ministry, Northeast Agricultural University, Harbin 150030, China

\section{Zhang Y., Zhang N., Chen D., Huang G., Cao H. \\ Investigation of the transport of aflatoxin M1 by the transporter ABCG2 in bovine mammary epithelial cells}

\section{Summary}

Aflatoxin M1 (AFM1), a hydrogenated metabolite of aflatoxin B1 (AFB1), is one of the most common and threatening aflatoxins found in milk and dairy products. The ATP-binding cassette G2 efflux transporter (ABCG2) plays an important role in the mammary transport of drugs and toxins in animals, but whether ABCG2 could affect the transport of AFM1 in bovine mammary epithelial cells (BMECs) has not been clarified. Therefore, this study aimed to investigate the effects of AFM1 on tight junctions (TJs), lactation and cells proliferation in BMECs, and explored the regulatory role of ABCG2 in AFM1 transport in vitro in BMECs. The results showed that the integrity of the TJs of BMECs was not permanently compromised after exposure to AFM1. AFM1 exposure had no obvious effects on lactation or cell proliferation in BMECs. Gene function study revealed that $A B C G 2$ was a positive regulator of AFM1 transport. These results demonstrate that it has little effect on TJs, lactation or cell proliferation in BMECs exposed to a small dose of AFM1, and ABCG2 is a critical regulator for AFM1 transport in BMECs.

Keywords: AFM1, bovine mammary epithelial cells, ABCG2, transport, tight junctions

Aflatoxin (AF) is a type of mycotoxin produced by Aspergillus fungi that is classified according to the following categories: AFB1, AFB2, AFG1, and AFG2 (9, 17). AFM1, as a 4-hydroxy metabolite of AFB1, has been classified as a carcinogen II (3). AFM1 has strong carcinogenicity and mutagenicity and is the most toxic AF after AFB1 (20). It can cause liver necrosis, lung cancer, stomach cancer, colon cancer, and kidney tumors (28). AFM1 is a common aflatoxin in milk and dairy products, and it enters cow milk mainly through the consumption by cows of feed contaminated with AFB1 (26).

There is a wide variation in AFM1 levels among milk and other dairy products in different geographical regions $(12,21)$. Compared to the extensive study of the toxicities and metabolism of AFB1, there is limited data on the potential risk of exposure to AFM1 from milk and other dairy products and on the metabolism, toxicity, and transport of this molecule, particularly in dairy cows.

\footnotetext{
1) This study was supported by Project of the Ministry of the University Nursing Program for Young Scholars with Creative Talents in Heilongjiang Province of China (Project No. UNPYSCT-2016147).
}

Tight junctions (TJs) between bovine mammary epithelial cells (BMECs) are a natural barrier against AF after ingestion of contaminated food. TJs between adjacent epithelial cells, which are composed of tight junction proteins, such as ZO-1, linked adhesion molecules, and occludin, form an effective barrier $(1,6)$. In epithelial tissues, the initial toxic effects of some substances have a direct effect on molecules involved in junction complexes. Because the dynamic structure of TJs can respond rapidly to several physiological and pathological stimuli, modulation of the barrier properties is often reflected by changes in specific TJ protein components.

Because of its low molecular weight, AFM1, after ingestion, can cross the cytomembrane into cells by a passive mechanism (30). However, previous studies have demonstrated that AFB1 is secreted into milk through $\mathrm{ABCG} 2$ transport in murine mammary epithelial cells (8). Because the ligand transported by $\mathrm{ABCG} 2$ has many similarities to AFM1, AFM1, as a metabolite of AFB1, may also be carried by the transporter $\mathrm{ABCG} 2(24,25)$. 
The ATP-binding cassette G2 efflux transporter (ABCG2), also called breast cancer resistance protein (BCRP), is expressed in epithelial cells in many tissues, including the liver, kidneys, intestine, placenta and several blood-tissue barriers (16), and it mediates the disposition and excretion of numerous endogenous drugs and toxins $(11,31)$. It is expressed in mammary glands, including those in humans, cows, and mice, and mediates the secretion of some veterinary drugs and food contaminants into milk (10). It also plays a key regulatory role in cellular protection and detoxification. However, specific mechanisms mediated by ABCG2 in bovine mammary epithelial cells have not been completely clarified. To date, a number of model systems have been developed to study the ability of aflatoxins to serve as substrates of ABCG2.

Research on the regulatory mechanisms of drugs and toxins transported in BMECs is relatively novel. Therefore, the present study investigated the possible damage caused by AFM1 to tight junctions of BMECs and its effects on lactation and cell proliferation. We also investigated whether the transport of AFM1 is mediated through ABCG2. These results may provide basic data and a theoretical basis for reducing the amount of contaminated milk and dairy products and ensuring the safety of dairy production.

\section{Material and methods}

Cell culture. BMECs were isolated from the mammary gland tissues of Holstein dairy cows according to protocols described in previous reports (7). The purity of the cells was evaluated by immunofluorescence detection of the expression of cytokeratin 18. The BMECs were cultured in DMEM-F12 (Gibco, Thermo Fisher Scientific, Waltham, USA) supplemented with $10 \%$ FBS (Gibco, Thermo Fisher Scientific, Waltham, USA), penicillin $(100 \mathrm{U} / \mathrm{mL})$, and streptomycin $(0.1 \mathrm{mg} / \mathrm{mL})$. The cells were grown in a basal DMEM/F12 medium containing 10\% FBS in a humidified chamber at $37^{\circ} \mathrm{C}$. To observe the effects of AFM1 on the expression of ABCG2, the cells were divided into two groups, and the cells in each group were counted. One group was incubated with different concentrations of AFM1 (Sigma-Aldrich, St. Louis, USA) (0.16, 0.32, 1.6, 3.2 and $16 \mathrm{nM}$ ) for $12 \mathrm{~h}$. The other group was treated with AFM1 at $0.32 \mathrm{nM}$ for different periods $(1,6,12,18,24,48$ and $96 \mathrm{~h}$ ). Then, the cells were subjected to different assays, as described below.

Cell morphology under scanning electron microscopy. BMECs were seeded on glass coverslips at $80-90 \%$ confluence in six-well plates. The cells were rinsed twice with PBS and fixed in $\mathrm{pH} 7.2$ glutaraldehyde at $4{ }^{\circ} \mathrm{C}$ for $60 \mathrm{~min}$. The slides were rinsed three times with $0.1 \mathrm{M} \mathrm{PBS}(\mathrm{pH} 7.2)$ for $10 \mathrm{~min}$. Then, the cells were dehydrated with $50 \%, 70 \%$ and $80 \%$ ethanol for 15 min each time and dehydrated with absolute ethyl alcohol for $15 \mathrm{~min}$ three times. The cells were incubated with a mixed solution of $10 \%$ ethanol and tertbutyl alcohol (ethanol: tert-butyl alcohol $1: 1$ ) for $15 \mathrm{~min}$ at room temperature, and then treated with pure tert-butyl alcohol for $15 \mathrm{~min}$ at $37^{\circ} \mathrm{C}$. We removed coverslips from the 6-well plate, placed each in a small dish, added pure text-butyl alcohol, and incubated them at $-20^{\circ} \mathrm{C}$ for $30 \mathrm{~min}$; then, we placed the dish in an es-2030 freeze-dryer (Hitachi, Tokyo, Japan) to dry the sample for $4 \mathrm{~h}$. A metal film of $100 \times 150 \mathrm{~A}$ a was coated on the surface of the sample by an e-1010 ion sputter coating instrument. The coverslips were visualized with a scanning electron microscope.

Immunofluorescence. BMECs were seeded on glass coverslips and grown to $30-50 \%$ confluence in six-well plates. The cells were rinsed twice with PBS and fixed in $4 \%$ $(\mathrm{w} / \mathrm{v})$ ice-cold formaldehyde at $4^{\circ} \mathrm{C}$ for $10 \mathrm{~min}$. The slides were rinsed three times with $\mathrm{PBS} / \mathrm{T}$ for $5 \mathrm{~min}$. To detect ZO-1 and endogenous cytokeratin 18 (CK18), the fixed BMECs were incubated in blocking buffer for $1 \mathrm{~h}$ at $37^{\circ} \mathrm{C}$ and then incubated with anti-CK18 (Bioss, Beijing, China) or anti-ZO-1 primary antibody (Abbiotec, San Diego, USA) at a $1: 100$ dilution overnight at $4^{\circ} \mathrm{C}$. After rinsing three times in PBS/T, the specimens were incubated in the dark with FITC-conjugated secondary antibodies at a $1: 200$ dilution for $1 \mathrm{~h}$ at $37^{\circ} \mathrm{C}$ and incubated with PI or DAPI for $15 \mathrm{~min}$ at $37^{\circ} \mathrm{C}$. Finally, after rinsing three times in PBS/T, the coverslips were visualized with a Leica TCS-SP2 AOBS confocal laser scanning microscope (15).

Western blotting. Western blotting assays were carried out as previously described (23). The primary antibodies were as follows: anti-BCRP/ABCG2 antibody (Abcam, Cambridge, USA), $\beta$-casein antibody (Santa Cruz Biotechnology, CA, USA), and $\beta$-actin antibody (Bioss, Beijing, China). Next, the membranes were incubated at $37^{\circ} \mathrm{C}$ for $1 \mathrm{~h}$ with the corresponding horseradish peroxidase (HRP)-conjugated secondary antibodies (Biosharp, Hefei, China) after extensive washing. Finally, protein bands were detected using enhanced chemiluminescence (ECL) reagents (Biosharp, Hefei, China) and analyzed by the ImageJ software. Protein levels were normalized to $\beta$-actin.

Cell Viability Assay. Cell viability was determined with a CASY-TT Analyser System (Scharfe System GmbH, Reutlingen, Germany), which was used for automated cell counting and measurement of viability according to the size of the cells. Live cells with an intact cell membrane could be considered as electrical isolators, and the resistance measurement reflected the true size of the living cell, while dead cells were identified by the size of their nucleus. Cell debris was less than $7.63 \mathrm{~mm}$, the dead cells were between 7.63 and $11.75 \mathrm{~mm}$, and the live cells were larger than $11.75 \mathrm{~mm}$. After calibration with dead and live cells, the cursor positions were set to 11.75 to $50.00 \mathrm{~mm}$ (evaluation cursor) and 7.63 to $50.00 \mathrm{~mm}$ (standardization cursor) for the analysis of cell viability.

RNA Extraction and Real-Time Quantitative PCR. BMECs total RNA was isolated using TRIzol reagent (Thermo Fisher Scientific, Waltham, USA). Reverse transcription was performed with a total RNA sample $(1 \mu \mathrm{g})$ and Thermoscript reverse transcriptase (TaKaRa, Dalian, China). qRT-PCR reactions were performed with a qRTPCR System (ABI PRISM 7 300, Applied Biosystems, Foster City, CA, USA) with $\beta$-actin mRNA, which was used as an internal control. The primers used to amplify the ABCG2 transcript were as follows: sense 5'-TAGCAGCAGGTCAGAGTGTGG-3', antisense 5'-CATGACAAC- 
CAAGGCACGAC-3'. The primers used to amplify $\beta$-actin were the following: sense 5'-AAGGAAATCTACGCCAACACG-3', antisense 5'-TTTGCGGCGGACGGTAGAG-3'. The relative expression of $\mathrm{ABCG} 2 \mathrm{mRNA}$ was calculated by the $2^{-\Delta \Delta C \mathrm{~T}}$ method.

ABCG2 overexpression. The CDS sequence of bovine ABCG2 (NM 001082424.1) was amplified from the BMECs cDNA and subcloned into an expression vector, which was completely sequenced. This work was completed by the GenePharma Company (Suzhou, China). Cells were transfected with the recombinant plasmid using Lipofectamine 2000 (Thermo Fisher Scientific, Waltham, USA). The primers used for amplification were as follows: sense, 5'-GGAATTCCCTGAAGGAGCTGTGTTAAG-3' (EcoR I); antisense, 5'-CGAGCTCGTGCCACTTTATCCAGACCT-3' (Sal I). Cells transfected with the empty vector $(\mathrm{EV})$ and untransfected cultured cells were both used as controls. Cells were harvested at $24 \mathrm{~h}$ post-transfection.

ABCG2 knockdown. Three specific siRNAs against different sequences of ABCG2 mRNA and the negative control siRNA (NC) were synthesized by the GenePharma Company. The most effective siRNA of the three was selected by transfection experiments using Lipofectamine 2000. The selected ABCG2 siRNA sequences were as follows: sense, 5'-CCUACUUAGUCUCUUUATT-3', antisense, 5'-UAAAGAGACUAAGUAGGCTT-3'. Cells transfected with the $\mathrm{NC}$ and untransfected cultured cells were used as controls. Cells were harvested at $24 \mathrm{~h}$ post-transfection.

HPLC. AFM1 standards were detected by HPLC at different concentrations of $0.016,0.032,0.064,0.128$ and $0.256 \mathrm{nM}$. The cell lysis solution and culture supernatants
A DAPI

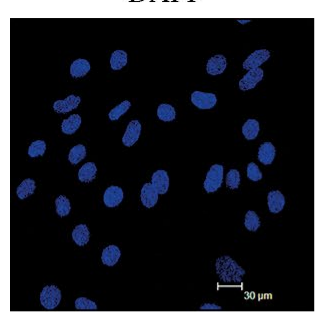

CK18

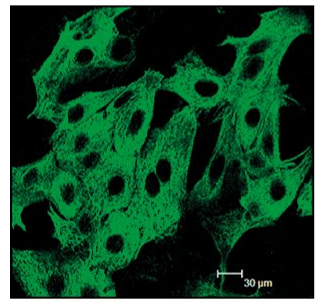

Merge

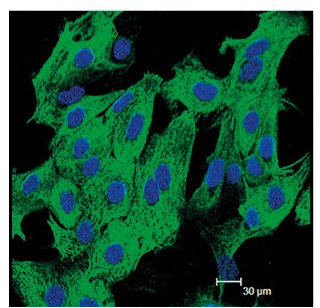

B

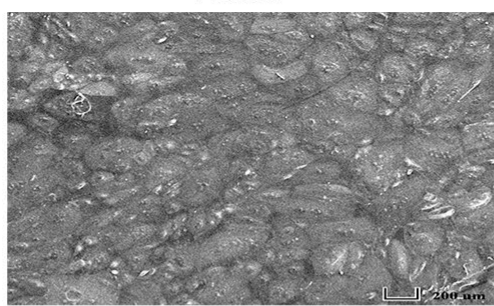

C

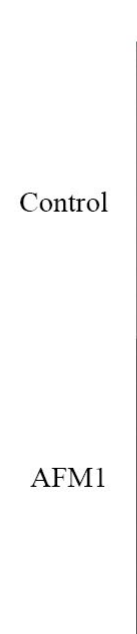

DAPI

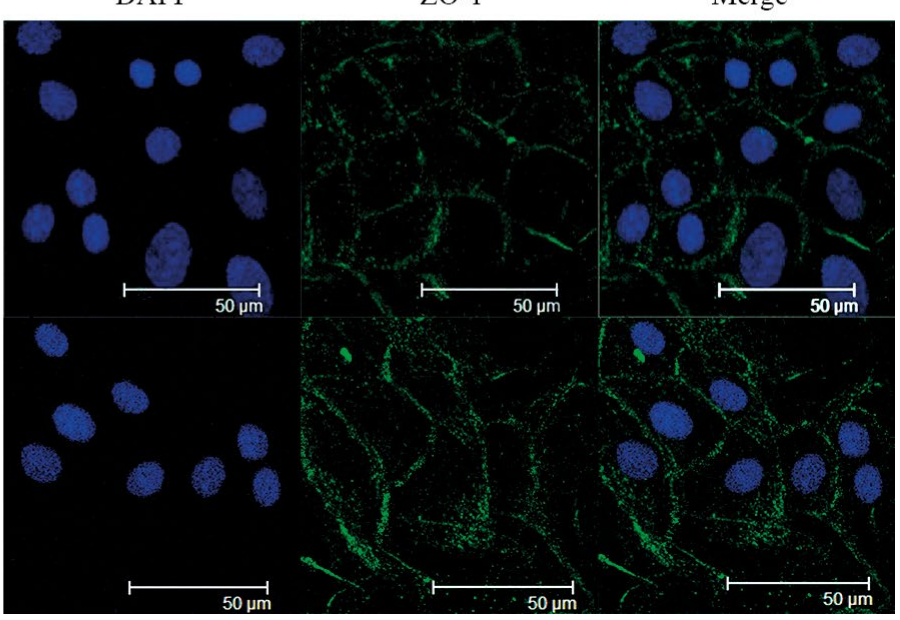

Fig. 1. Effects of AFM1 on the cellular structure. A, B - The morphology of BMECs under a scanning electron microscope. $\mathrm{C}$ - Expression of ZO-1 in cells observed by immunofluorescence staining were then filtered through a $0.22 \mu \mathrm{m}$ membrane. The detection conditions of HPLC were as follows: The chromatographic column was $\mathrm{C} 18(\Phi 150 \times 4.6 \mathrm{~mm}, 5 \mu \mathrm{m})$, the column temperature was $35^{\circ} \mathrm{C}$, the detection wavelength was $435 \mathrm{~nm}$, the mobile phase was $5 \%$ to $0.1 \%$ formic acid solution and acetonitrile-methanol solution $(1: 1)$, the sample was treated by filtration with a $0.22 \mu \mathrm{m}$ membrane and ultrasonic degasification, the constant current was $0.3 \mathrm{~mL} / \mathrm{min}$, and the injection volume was $10 \mu \mathrm{L}$.

Statistical analysis. All data are presented as the mean \pm standard error from three independent experiments. Statistical analysis was performed by the IBM SPSS Statistics 21 software. Student's t-test or one-way analysis of variance was used to determine differences between means. Statistical significance was set at $\mathrm{p}<0.05$ or $\mathrm{p}<0.01$.

\section{Results and discussion}

Effect of AFM1 on cellular structures. The purity of the primary BMECs isolated by the tissue block method was verified by immunofluorescence observation of the strong positive signal of CK18, a marker protein expressed by epithelial cells (Fig. 1A). To see whether AFM1 caused damage to the cells, the morphology of the BMECs treated with AFM1 at $0.32 \mathrm{nM}$ for $12 \mathrm{~h}$ was observed under a scanning electron microscope. The results showed the cells were shaped like irregular polygons and formed a cobblestone-like appearance (Fig. 1B), indicating that the addition of AFM1 caused no distinct damage to cell structures. Then, we detected the expression of ZO-1. After the $12 \mathrm{~h}$ treatment with AFM1 at $0.32 \mathrm{nM}$, no loss of ZO-1 was observed, indicating it had not damaged the integrity of TJs (Fig. 1C). These findings indicate that there were no apoptotic changes induced by the $12 \mathrm{~h}$ exposure to AFM1 at a concentration of $0.32 \mathrm{nM}$.

Effect of AFM1 on lactation function and proliferation of BMECs. The effects of AFM1 on lactation function and cell proliferation were also determined. Western blotting analysis showed that treatment with AFM1 had no significant effect $(p>0.05)$ on the protein expression of $\beta$-casein (Fig. 2A to 
$\mathbf{A}$

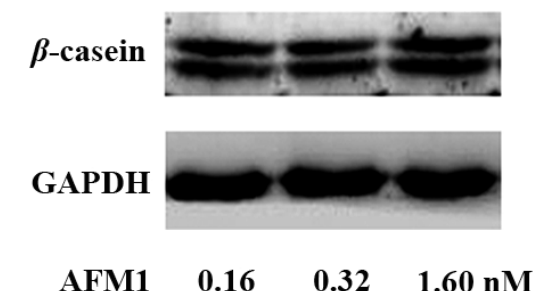

C

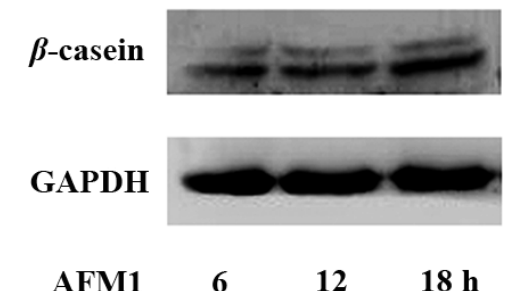

$\mathbf{E}$

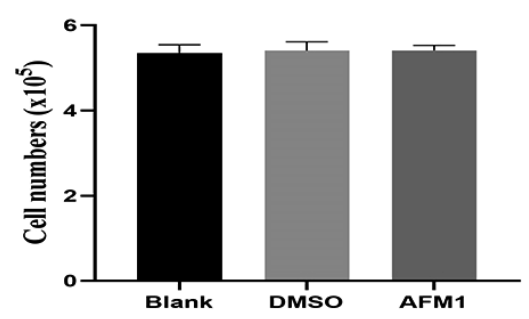

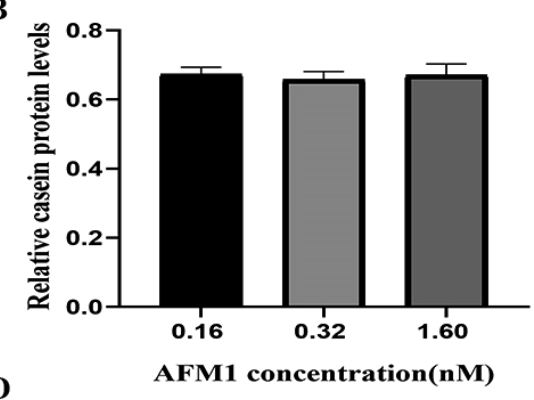

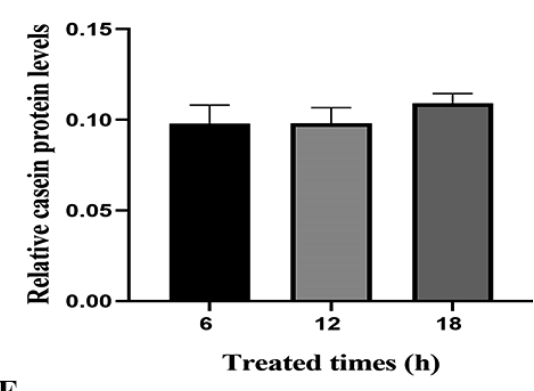

$\mathbf{F}$

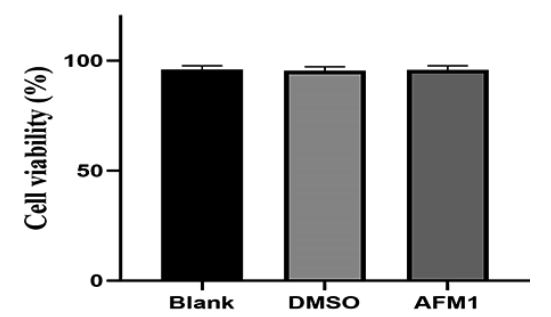

Fig. 2. Effects of AFM1 on lactation and proliferation of BMECs. A, B - The protein levels of $\beta$-casein measured by western blotting. $C, D$ - Relative folds of $\beta$-casein quantified by grayscale scanning. $E, F-$ The number and viability of cells determined by an automatic cell counter

Explanations: Data are presented as mean \pm SEM. ${ }^{*}-\mathrm{p}<0.05, * *-\mathrm{p}<0.01$.

A

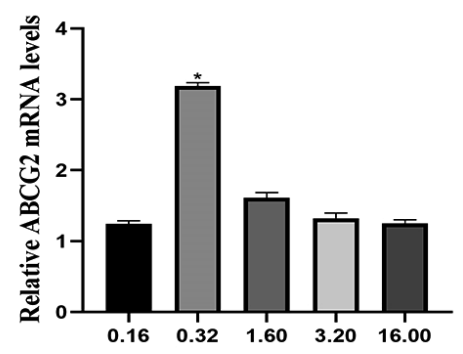

D

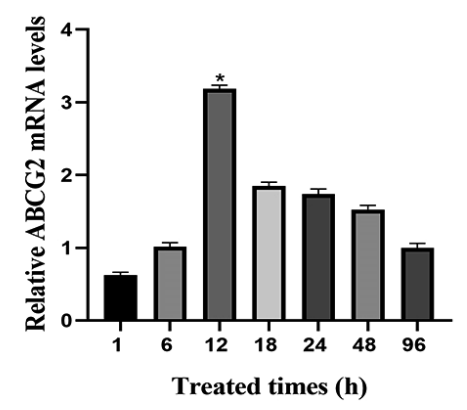

B

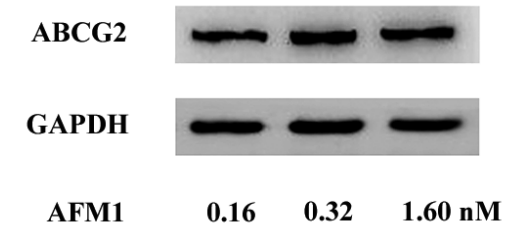

$\mathbf{E}$

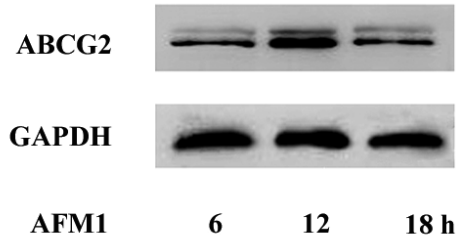

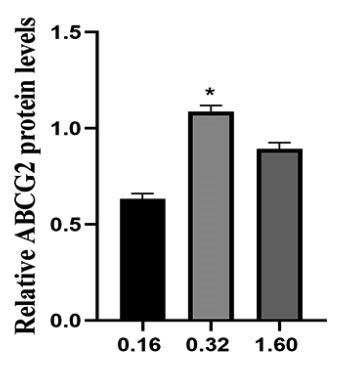

$\mathbf{F}$

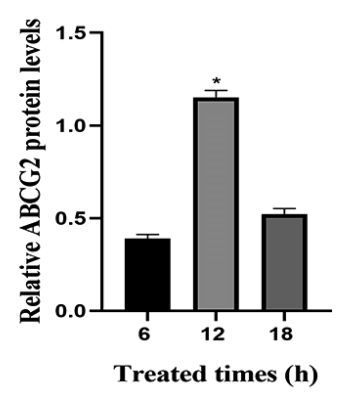

Fig. 3. Effects of AFM1 on ABCG2 expression. A, D - ABCG2 mRNA levels in treated cells measured by qRT-PCR. B, E - The protein levels of ABCG2 measured by western blotting analysis. C, F - Relative folds of ABCG2 quantified by grayscale scanning

Explanations: as in Fig. 2.

D). The results of the cell viability assay showed that the treatment with AFM1 had no significant effect $(p>0.05)$ on cell proliferation either (Fig. 2E and F). These results indicate that a low dose of AFM1 caused only minor damage to the cells, which was not sufficient to affect lactation function or cell proliferation.

Effect of AFM1 on the expression of the exogenous compound transporter ABCG2 in BMECs. To determine the effects of AFM1 on the expression of ABCG2 in BMECs, the cells were divided into two groups. One group was incubated with different concentrations of AFM1 $(0.16,0.32,1.6,3.2$ and $16 \mathrm{nM})$ for $12 \mathrm{~h}$. The other group was treated with AFM1 at $0.32 \mathrm{nM}$ for different periods $(1,6,12,18,24,48$ and $96 \mathrm{~h})$. As the AFM1 concentration increased, the mRNA levels of ABCG2 in the BMECs initially increased, peaked at $0.32 \mathrm{nM}$ $(p<0.05)$, and then decreased gradually (Fig. 3A). As the AFM1 incubation time increased, the mRNA levels of ABCG2 in the BMECs initially increased, peaked at $12 \mathrm{~h}(\mathrm{p}<0.05)$, and then decreased gradually (Fig. 3D). The results of the western blotting were consistent with the qRT-PCR results (Fig. 3B and C, E and $F)$. The results show that the maximal effects of AFM1 on ABCG2 were achieved at a concentration of $0.32 \mathrm{nM}$ after incubation for $12 \mathrm{~h}$. Therefore, a dose of $0.32 \mathrm{nM}$ and a $12 \mathrm{~h}$ incubation period were used in the following experiments.

Effect of ABCG2 on AFM1 transport in BMECs. The cells were seeded on top of the polycarbonate membrane of the Transwell chamber and incubated in 6-well plates until the cells were completely confluent on the polycarbonate membrane. The cells were transfected to overexpress $\mathrm{ABCG} 2$, or 
it was knocked down by transfection with a siRNA against ABCG2 mRNA for $24 \mathrm{~h}$. Then, $0.32 \mathrm{nmol} / \mathrm{L}$ AFM1 was added to the lower chamber of the Transwell chamber, and we collected the BMECs and the culture medium from the upper chamber $12 \mathrm{~h}$ later (Fig. 4A). The content of AFM1 in the cells and supernatant culture was measured by HPLC. The results of HPLC showed that $\mathrm{ABCG} 2$ overexpression significantly increased $(\mathrm{p}<0.05)$ the content of AFM1 in the BMECs (Fig. 4C) and in the supernatant culture (Fig. 4D). The results of ABCG2 knockdown had the opposite effect $(p<0.05)$ with regard to the level of AFM1 in the cells (Fig. 4E). The AFM1 content in the supernatant culture showed no significant differences $(\mathrm{p}>0.05)$ across all treatment groups (Fig. 4F). These data reveal that ABCG2 is a positive regulator of AFM1 transport in BMECs.

AFM1 is one of toxins found in contaminated milk from dairy cows, but the molecular mechanism of transport of AFM1 in bovine mammary epithelial cells is largely unknown.

TJs play an important role in preventing the entry of microorganisms and endotoxins $(2,27)$. At the same time, however, it can also be threatened by infecting microorganisms and endotoxins, which cause changes in the permeability
A

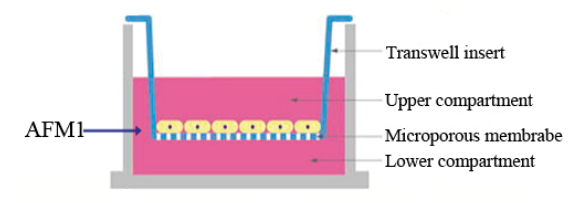

C

E

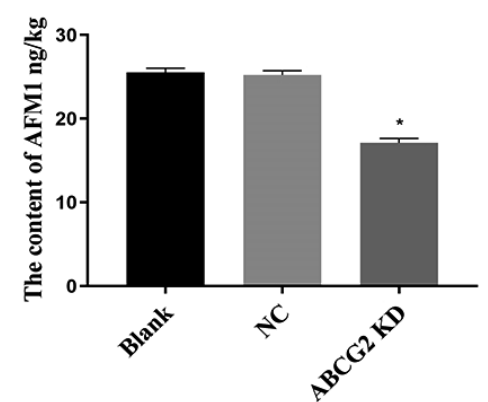

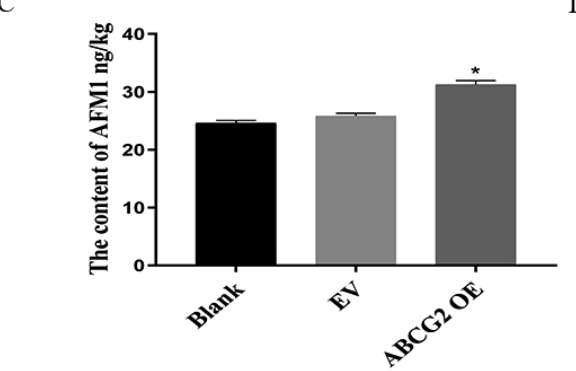

B
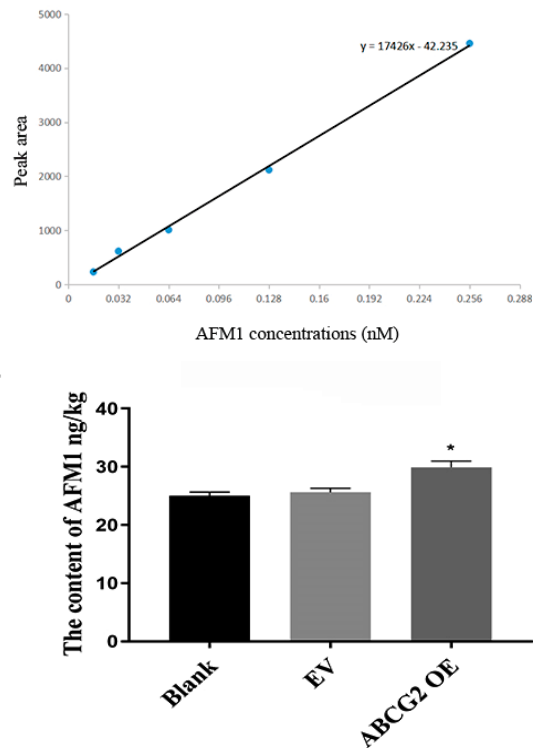

F

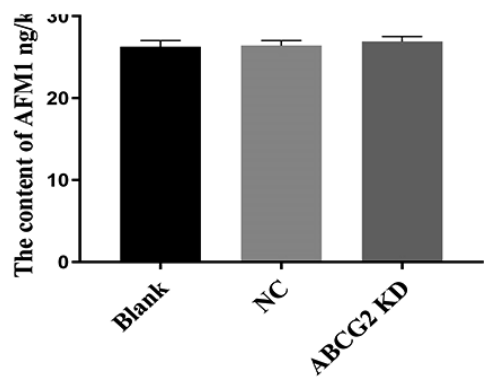

Fig. 4. Effects of ABCG2 overexpression or knockdown on AFM1 transport. A - The standard curve of AFM1 drawn by HPLC. B, C - The content of AFM1 in ABCG2 over-expression cells and the medium in the upper chamber of the Transwell insert. D, E - The content of AFM1 in ABCG2 interference cells and the medium in the upper chamber of the Transwell insert

Explanations: as in Fig. 2. of the epithelial barrier (4). In the mammary tissue of mice, the structures of TJs can change during delivery, lactation, and degeneration (19). Therefore, changes in the permeability of the epithelial barrier can be regarded as an early indicator of adverse effects after chemical exposure (23). The morphological examination by inverted scanning electron microscopy of TJs between cells showed that there was no significant difference between the control group and the AFM1treated group. The overall morphology of the cells remained unchanged. Immunofluorescence assays detected that ZO-1 showed strong peripheral labeling in the cellular compartments of the control and AFM1-treated groups, indicating that AFM1 caused little damage to the integrity of ZO-1. In these monolayer cells, all of their nuclei exhibited characteristic uniform fluorescent staining, suggesting that AFM1 did not induce apoptosis. This is consistent with previous reports from intracellular studies on human intestinal Caco-2/TC7 cells (5).

In some studies, AFB1 decreased cellular proliferation and induced apoptosis in an immortalized MAC-T cell line (18). Our experimental data showed that, with increases in the AFM1 concentration or treatment period, milk protein production and cell proliferation showed no significant changes, suggesting that the doses of AFM1 and the periods exposure to AFM1 used in this study may have little cytotoxic effect on cells. However, Li et al. showed that AFM1 induced apoptosis and decreased the proliferation of HEK293 cells (14). We believe that this difference may be due to different doses of AFM1 used as well as the fact that the cells came from diverse species and organs, which may have different levels of toleration of AFM1. Our results show that AFM1 is transported by BMECs, but does not participate in the regulation of proliferation or lactation in BMECs. Our results also indirectly prove that the process of AFB1 being metabolized into AFM1 in BMECs may be an approach to toxicity reduction (22). Therefore, our study further explored how AFM1 was transported in BMECs.

The transport of drugs in the body generally involves transporters. Specialized transporter proteins move exogenous compounds through membranes in BMECs (13). Some transporters, such as ABCG2, are involved in the transport of exogenous complexes (29). AF, as an environmental pollutant, is a ligand for ABCG2 and affects the expression of transporters 
(8). Our study demonstrates that AFM1 is a positive regulator of $\mathrm{ABCG} 2$ expression in BMECs. When the concentrations of AFM1 were below $0.32 \mathrm{nM}$, AFM1 dose-dependently stimulated increased the mRNA expression of ABCG2. With an increase in the concentration of AFM1 $(>0.32 \mathrm{nM})$, the stimulatory effect of AFM1 on the mRNA expression of ABCG2 gradually decreased. When cells were exposed to AFM1 for less than $12 \mathrm{~h}$, AFM1 time-dependently stimulated the mRNA expression of ABCG2. With an increase in the exposure period $(>12 \mathrm{~h})$, the stimulatory effect of AFM1 on the mRNA expression of ABCG2 gradually decreased. The results of western blotting were consistent with those of qRT-PCR. Our experimental data suggest that AFM1 can promote ABCG2 expression in BMECs at suitable concentrations and exposure periods, indicating the possibility of ABCG2 participating in AFM1 transport. Gene function study demonstrated that $\mathrm{ABCG} 2$ is a positive regulator of AFM1 transport, further revealing that ABCG2 is required for AFM1 transport.

In summary, our study demonstrates that the transporter ABCG2 transports AFM1 in BMECs. AFM1 is only involved in transport by BMECs and does not participate in the regulation of proliferation or lactation by BMECs. This conclusion can provide basic data and a theoretical basis for reducing the level of contamination in milk and dairy products, ensuring the safety of dairy production. However, the detailed mechanism of the transport of AFM1 by ABCG2 is uncertain and needs to be studied further in the future.

\section{References}

1.Abbott N. J., Patabendige A. A., Dolman D. E., Yusof S. R.: Structure and function of the blood-brain barrier. Neurobiol Dis. 2010, 37, 13-25.

2. Ahmad U. D., Adil H., Zhu Y., Zhang K., Wang Y., Li T., Wang Y., Wang G.: Inhibitory effect of Bifidobacterium bifidum ATCC 29521 on colitis and its mechanism. The Journal of Nutritional Biochemistry 2020, 79, doi: 10.1016/ j.jnutbio.2020.108353.

3. Awaisheh S. S., Rahahleh R. J., Algroom R. M., Al-Bakheit A. A., Al-Khaza'leh J. M., Al-Dababseh B. A.: Contamination level and exposure assessment to Aflatoxin M1 in Jordanian infant milk formulas. Italian Journal of Food Safety 2019, 8, 8269 .

4. Bonazzi M., Cossart P.: Impenetrable barriers or entry portals? The role of cell-cell adhesion during infection. J. Cell. Biol. 2011, 195, 349-358.

5. Caloni F., Cortinovis C., Pizzo F., De Angelis I.: Transport of aflatoxin M 1 in human intestinal Caco-2/TC7 cells. Front Pharmacol. 2012, 3, 111, doi 10.3389/fphar.2012.00111.

6. Chiba H., Osanai M., Murata M., Kojima T. Sawada N.: Transmembrane proteins of tight junction. Bba-Biomembranes 2008, 1778, 588-600.

7. Cui Y., Liu Z., Sun X., Hou X., Qu B., Zhao F., Gao X., Sun Z., Li Q.: Thyroid hormone responsive protein spot 14 enhances lipogenesis in bovine mammary epithelial cells. J. In Vitro Cell. Dev-An. 2015, 51, 586-594.

8. Herwaarden A. E. V., Wagenaar E., Karnekamp B., Merino G., Jonker J. W., Schinkel A. H.: Breast cancer resistance protein (Bcrp1/ABCG2) reduces systemic exposure of the dietary carcinogens aflatoxin B1, IQ and Trp-P-1 but also mediates their secretion into breast milk. Carcinogenesis 2006, 27, 123-130.

9. Jermnak U., Yurayart C., Poapolathep A., Poapolathep S., Imsilp K., Tanhan P., Limsivilai $O$.: Evaluation of Aflatoxin Concentrations and Occurrence of Potentially Toxigenic Fungi in Imported Chia Seeds Consumed in Thailand. Journal of food protection 2020, 83, 497-502.

10. Jonker J. W., Merino G. S., Van Herwaarden A. E., Bolscher E., Wagenaar E., Mesman E., Dale T. C., Schinkel A. H.: The breast cancer resistance protein
BCRP (ABCG2) concentrates drugs and carcinogenic xenotoxins into milk. J. Nat. Med. 2005, 11, 127-129.

11. Jonker J. W., Smit J. W., Brinkhuis R. F., Maliepaard M., Beijnen J. H., Schellens J. H., Schinkel A. H.: Role of breast cancer resistance protein in the bioavailability and fetal penetration of topotecan. JNCI-J. Natl. Cancer I. 2000, 92, 1651-1656.

12. Khaneghahi A. H., Bahonar A., Noori N., Yazdanpanah H.: The overall and variations of Aflatoxin M1 contamination of milk in Iran: A systematic review and meta-analysis study. Food chemistry 2020, 310, doi: 10.1016 j.foodchem.2019.125848.

13. Klaassen C. D., Lu H.: Xenobiotic transporters: ascribing function from gene knockout and mutation studies. Toxicol. Sci. 2008, 101, 186-196.

14. Li L., Li S., Yang H., Wang Y., Wang J., Zheng N.: 1-Proline alleviates kidney injury caused by AFB1 and AFM1 through regulating excessive apoptosis of kidney cells. Toxins 2019, 11, 226, doi: 10.3390/toxins 11040226.

15. Li X., Li P., Wang L., Zhang M., Gao X.: Lysine Enhances the Stimulation of Fatty Acids on Milk Fat Synthesis via the GPRC6A-PI3K-FABP5 Signaling in Bovine Mammary Epithelial Cells. J. Agric. Food. Chem. 2019, 67, 7005-7015 .

16. Maliepaard M., Scheffer G. L., Faneyte I. F., Gastelen M. A., Pijnenborg A. C., Schinkel A. H., van De Vijver M. J., Scheper R. J., Schellens J. H.: Subcellular localization and distribution of the breast cancer resistance protein transporter in normal human tissues. Cancer Res. 2001, 61, 3458-3464.

17. Najmeh S. T., Mohammad M. F., Rasoul R. B., Nezhat J., Ebrahim R., Forogh R.: A facile one-pot green synthesis of $\beta$-cyclodextrin decorated porous graphene nanohybrid as a highly efficient adsorbent for extracting aflatoxins from maize and animal feeds. Food Chemistry 2020, 311, doi: 10.1016 j.foodchem.2019.125747.

18. Park W., Park M. Y., Song G., Lim W.: Exposure to aflatoxin B1 attenuates cell viability and induces endoplasmic reticulum-mediated cell death in a bovine mammary epithelial cell line (MAC-T). Toxicol In Vitro 2019, 61, doi: 10.1016/j.tiv.2019.104591.

19. Pitelka D. R., Hamamoto S. T., Duafala J. G., Nemanic M. K.: Cell contacts in the mouse mammary gland. J. Mammary Gland Biol. 2009, 14, 295-316.

20. Prandini A., Tansini G., Sigolo S., Filippi L., Laporta M., Piva G.: On the occurrence of aflatoxin M 1 in milk and dairy products. Food Chem. Toxicol. 2009, 47, 984-991

21.Rouaa D., Charbel A., Karine J., Lydia R. K., Richard M., Ali I., André E. $K$.: Occurrence of aflatoxin M 1 in raw, pasteurized, UHT cows' milk, and dairy products in Lebanon. Food Control 2020, 111, doi: 10.1016/ j.foodcont.2019.107055.

22. Sadeghi N., Oveisi M. R., Jannat B., Hajimahmoodi M., Bonyani H., Janna F. Incidence of aflatoxin M 1 in human breast milk in Tehran. Iran, Food Control 2009, 20, 75-78.

23. Sambuy Y.: Molecular and Cellular Aspects of Toxicology, [in:] Casciano D. A. Sahu S. C., Ballantyne B., Marrs T., Syversen T. (eds.): General, Applied and Systems Toxicology, John Wiley \& Sons, London 2009, p. 345-365.

24. Sarkadi B., Ozvegy-Laczka C., Nemet K., Varadi A.: ABCG2-a transporter for all seasons. FEBS Lett. 2004, 567, 116-120.

25. Schinkel A. H., Jonker J. W.: Mammalian drug efflux transporters of the ATP binding cassette (ABC) family: an overview. Adv. Drug Deliver. Rev. 2012 64, 138-153.

26. Trucksess M., Richard J., Stoloff L., McDonald J. S., Brumley W. C.: Absorption and distribution patterns of aflatoxicol and aflatoxins B 1 and M 1 in blood and milk of cows given aflatoxin B 1. Am. J. Vet. Res.1983, 44, 1753-1756.

27. Ulluwishewa D., Anderson R. C., McNabb W. C., Moughan P. J., Wells J. M., Roy N. C.: Regulation of tight junction permeability by intestinal bacteria and dietary components. J. Nutr. 2011, 141, 769-776.

28. Virdis S., Corgiolu G., Scarano C., Pilo A. L., De Santis E. P. L.: Occurrence of aflatoxin M1 in tank bulk goat milk and ripened goat cheese. Food Control 2008, 19, 44-49

29. Wang J., Wang J. O., Cai C. Y., Cui O., Yang Y., Wu Z. X., Dong X., Zeng L., Zhao L., Yang D. H., Chen Z. S.: Reversal Effect of ALK Inhibitor NVP-TAE684 on ABCG2-Overexpressing Cancer Cells. Frontiers in oncology 2020, 10, 228, doi: 10.3389/fonc.2020.00228

30. Yiannikouris A., Jouany J. P.: Mycotoxins in feeds and their fate in animals: a review. Animal Research 2002, 51, 81-99.

31. Zhang S., Yang X., Morris M. E.: Flavonoids are inhibitors of breast cancer resistance protein (ABCG2)-mediated transport. Mol. Pharmacol. 2004, 65, 1208-1216.

Corresponding author: Na Zhang. The Key Laboratory of Dairy Science of Education Ministry, Northeast Agricultural University, Harbin 150030 China; e-mail: nazhang1981@126.com 